\title{
Design led innovation: Shifting from smart follower to digital strategy leader in the Australian airport sector
}

\author{
Rebecca Price \\ School of Design \\ Queensland University of Technology \\ Brisbane, Australia \\ r5.price@qut.edu.au \\ Cara Wrigley \\ School of Design \\ Queensland University of Technology \\ Brisbane, Australia
}

\author{
Alexander Dreiling \\ School of Information Systems \\ Queensland University of Technology \\ Brisbane, Australia
}

\author{
Sam Bucolo \\ School of Business \\ University of Technology Sydney \\ Sydney, Australia
}

\begin{abstract}
This paper presents and discusses organisational barriers and opportunities arising from the dissemination of design led innovation within a leading Australian airport corporation. This research is part of a greater action research program which aims to integrate design as a strategic capability through design led innovation within Australian businesses. Findings reveal that there is an opportunity to employ the theoretical framework and tools of design led innovation in practice to build collaborative idea generation by involving customers and stakeholders within the proposal of new to world propositions. The iterative gathering of deep customer insights also provided an opportunity to leverage a greater understanding of stakeholders and customers in strengthening continuing business partnerships through co-design. Challenges to the design led approach include resistance to the exploratory nature of gathering deep customer insights, the testing of long held assumptions and market data, and the disruption of an organisational mindset geared toward risk aversion instilled within the aviation industry. The implication from these findings is that design led innovation can provide the critical platform to allow for a business to grow and sustain internal design capabilities necessary to challenge prevailing assumptions about how its business model operates to deliver value to customers and stakeholders alike. The platform of design led innovation also provides an avenue to support a cultural transformation towards anticipating future needs necessary for establishing a position of leadership within the broader economic environment.
\end{abstract}

Keywords-innovation, digital economy, design thinking, customer relationships, action research

\section{INTRODUCTION}

Airports are an integral part of the aviation industry providing critical infrastructure and services that make possible the air transportation of people and goods. The privatisation of the airport businesses occurred widely in the 1980s under increasing demand for capacity, airline growth and an unsustainable pressure on governments to operate airport infrastructures [1]. Airports still operate under strict government regulations founded on safety and security. As such, the underlying business model of airports acts as the platform for successful operation of core business - the departure and arrival of flights as the key service to passengers. However, airport business models have grown well beyond supporting essential operational activities alone [2]. Airports now seek to develop global networks, meet the unique needs and desires of passengers, whilst leveraging strategic opportunities that support the act of providing a gateway into countries, regions and continents [2].

In the last decade, this shift towards leveraging the strategic opportunities within business to business relationships, particularly with airlines, has firmed as the typology of airport business models [3]. A proposed future aerotropolis airport model argues that airports act as cities, home to people, businesses, industries, and a pivot point for economic growth [4] has been driven by the increasing modern urban dependence on air travel [5]. A cultural and organisational transformation within the airport sector supported by business model innovations will be required to accompany such a monumental shift toward the future operation of airports. Design led innovation offers a platform to structure an organisational transformation toward aligning the unique needs of customers to in this case, an airport's strategy for growth and vision for future operation through business model innovation [6]. This paper reports on the organisational challenges and barriers of a leading Australian airport corporation journey toward integrating design as a strategic capability within a leading Australian airport corporation. The integration of design is founded on the key development of a digital strategy as part of the greater strategic ambitions of the 
airport. A design led innovation approach is being undertaken in the development of this digital strategy. This paper reports upon the organisational opportunities that have arisen from the design led approach to innovation, as well as organisational barriers to adopting design led innovation. Therefore this paper responds to the following two research questions: What are the arising opportunities from design led innovation within a leading Australian airport corporation? What are the organisational barriers to adopting design led innovation within a leading Australian airport?

\section{A. Design led innovation}

Design led innovation requires a company to have a vision for top line growth, which is based on deep customer insights and expanded through customer and stakeholder engagements [6]. The outcome of design led innovation is the integration of design and a culture of design thinking within all aspects of a business to enable that vision to be achieved. prototyping and improving upon possible solutions [9], whilst simultaneously synthesising the user's needs and desires with what is viable and feasible $[12,13]$. With this value in mind, the role of design has now progressed to an application within the strategic level of business.

The transition between a greater understanding of customers and the strategic alignment of a businesses' value proposition to customer needs is founded on the gathering of deep customer insights. Deep customer insights are generated within the design led innovation approach and enable a deeper understanding of the meanings and motives underpinning the behaviour [14] and choices of customers [15]. Deep customer insights form part of the larger design led journey, which aims to develop an internal cultural shift toward the strategic use of design as a capability within a business enabling alignment of customer needs to a vision for growth.

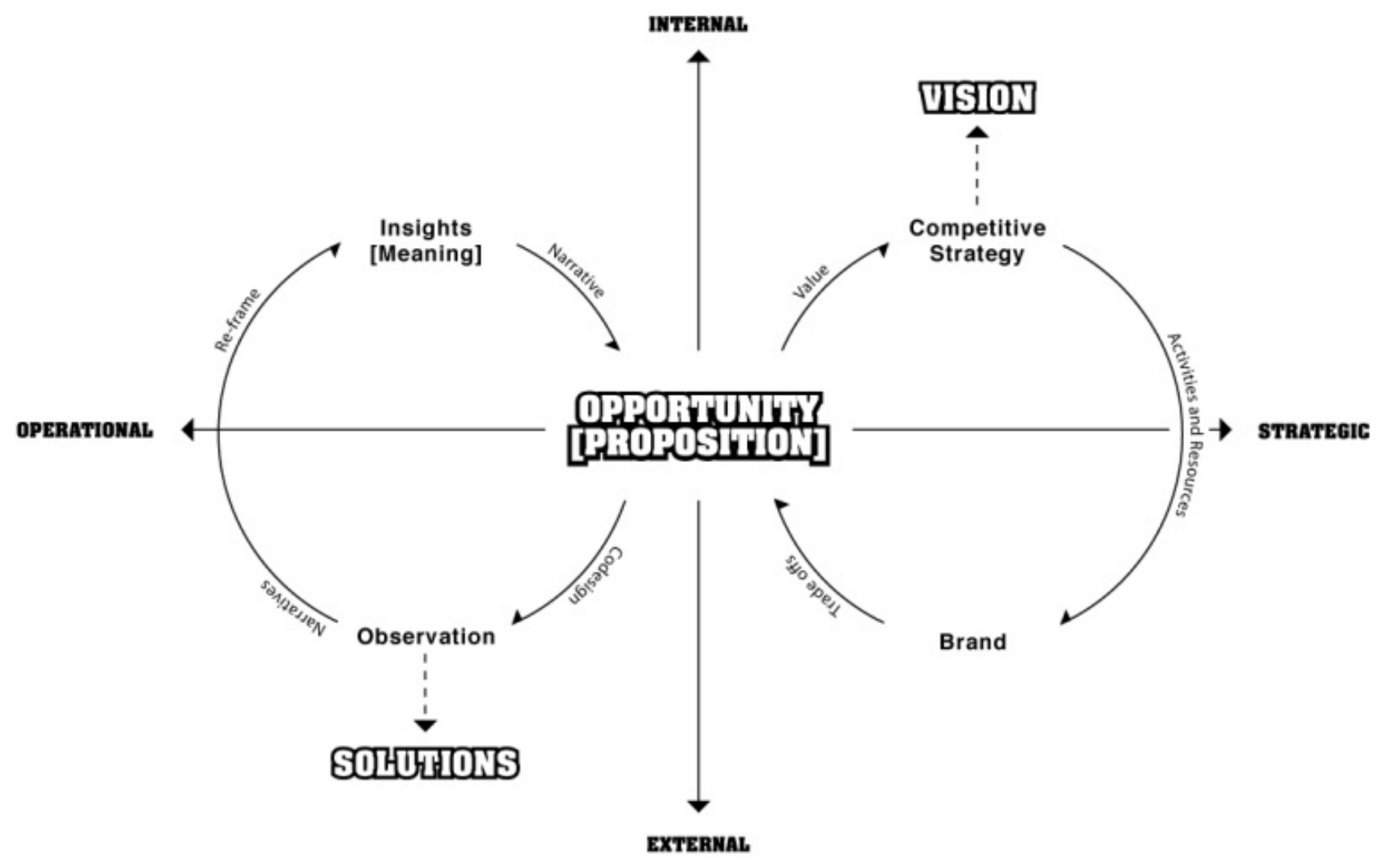

Fig 1. Design Innovation Framework [7]

Design thinking describes the way in which designers think, and the approaches and processes utilised in solving problems that may be wicked in nature [7]. Design and the culture of design thinking, is now perceived as an essential capability to creating and capturing new value through a better understanding of customers and their broader needs [8] that stems from the ability to frame problems [9]. The value of design lies in the way designers approach and solve problems [10]; typically from multiple perspectives [11], iteratively
The Design Led Innovation Framework (Fig. 1) illustrates the design led process, which begins by using design at the external and operational level of the business to gather deep customer insights [7].

Key design tools such as co-design [9], narratives and reframing [12], are used to develop insights and transfer these into tangible and relatable meanings with stakeholders through the composition of propositions. New propositions about the 
future can be tested and validated or critiqued by customers, stakeholders and business partners through co-design heavily communicated through narratives. In this case, propositions about the future digital strategy have been created, tested, with the findings interpreted to develop new deeper propositions about how a future digital strategy may deliver value to all stakeholders. Deep customer insights also provide the opportunity to fail fast in prototyping propositions in order to explore and identify potential irrelevancies surrounding any higher level concept. This approach encourages internal creativity, problem solving and critical thought, as well as empathy for the customer [13].

A proposition or business opportunity is then carried into the internal and strategic level of the business to inform strategy as a means for sustaining competitive advantages. A business model which is supportive of this cultural transformation can be designed and implemented with design integrating into all areas of a value chain. The potential for radical innovation of a business model is possible and is accompanied by the potential for a sustainable competitive advantage and accelerated growth protected by the new business model itself [16].

\section{B. The digital economy}

An emerging and integral opportunity of the airport sectors future is the development and integration of digital technology into physical infrastructure. Smart phones are widely considered an extension of the individual [17] such is the modern reliance on personal devices. Given this reliance, significant technological developments in content delivery which look to strategise ways of tailoring individualised content to the user are being explored [17]. Innovations in digital technology hold an ability to support the operation of the physical environment of an airport whilst creating new and potentially disruptive channels to customers and stakeholders [18]. The term disruptive innovation is used to describe innovations that are breakthrough or revolutionary in nature and drive a radical shift within the market toward the use of new services, products and businesses [19].

The digital economy has disrupted the traditional business model of airports which rely heavily on aeronautical revenue from the operation of airlines [18]. A diversification from the operation of physical infrastructure of terminals, runways and aircraft, provides an opportunity to develop new and stronger customer relationships which may support the growth of additional non-aeronautical revenue streams. The digital economy now also demands that individually tailored information is delivered to a customer in support of any interaction within a greater airport experience.

The rise of the digital economy presents an interesting link to the future aerotropolis business model [4] of airport operation. If airports become city like in nature, the population and residents of such a city will need to be interconnected not only through physical infrastructure, but also in the digital world. The digital environment presents an opportunity to integrate digital solutions with the physical environment through technology that meets the specific needs and desires of the end user. With any technology development presents the obvious questions: what problem does this technology solve? Within a design led approach to innovation, firstly understanding the needs and desires of customer is integral to selecting and implementing technology to improve customer experiences. At this point the paradigms of technology, user needs and business models converge with design led innovation offering the ability to synthesise these multiple viewpoints by aligning customer needs with a strategy for growth delivered in this case through a digital proposition [20]. A customer refocus toward improving and tailoring passenger experience to the individual lies ahead as one the greatest strategic opportunities in improving brand reputation and establishing a position of 'world best' within the airport sector and broader aviation industry as a whole.

\section{Smart follower to a position of leadership}

Digital strategy development within airports is a growing activity which moves away from the organisational culture supporting the development of the core business - the departure and arrival of flights. The internal cultural dynamic present within airport organisations, combined with the government regulations enforced on operations, gears airports organisations typically toward adopting innovations which are trialed and tested by early industry leaders [21]. The smart follower or innovation-adopting organization [22] selects and absorbs the success of innovation generators and leaders within and outside of their industry, reducing the risk of market failure. However, this approach toward innovation also cements risk and innovation adverse cultural dynamics within stakeholders which can yield low organizational creativity and deficiencies in problem solving [6]. For an airport striving to be in the 'world's best' category, the notion of smart following should be strategically addressed [23] through the development of its own clear strategies toward innovation. This does not negate the need to selectively smart follower based on a case by case basis, but rather integrating design can build the ability to take leadership when creative ideas are generated within the organisation. Pursuing a position of leadership within an industry requires a reconsideration of the firm strategy [24] towards growth, and an evaluation of the current airport business model [1]. These two activities are not easy to implement and require a structured approach.

The process of integrating a cultural transformation within an organisation is more difficult in practice than in theory and requires a structured approach to promote innovation, collaboration and leadership whilst also overcoming barriers to organisational change accompanying any uncertainty [25]. The design led innovation framework will be used to structure the development of the digital strategy within a major Australian airport corporation and by doing so, disrupt an organisations structure and culture toward innovation.

\section{RESEARCH DESIGN}

This research paper reports on the first 6 months of the 12 month embedded action research period within a major 
Australian airport. The paper presents the opportunities and barriers arising from a design led approach to innovation within the development of the digital strategy. The duration of this research protocol sees the researcher embedded within the airport corporation four days a week as a full time design led catalyst for the duration of 12 months [26]. The design led catalyst reports to a business performance manager who acts as a design champion within the firm, supporting and supervising the project from the airport's perspective. The researcher (first author) is based within the strategic planning and development group of the airport in a design led innovation research role with the purpose to, a) teach and facilitate other internal stakeholders through a design led approach to innovation, and b) lead the development of digital strategy through design led propositions. Placement within the airport corporation allows the single focus on 'understanding the dynamics present within a single setting' [27]. The data collection methods support the action research methodology which seeks to document challenges and opportunities that arise from integrating a design led approach within a leading Australian airport corporation.

\section{A. Methodology}

The practical and industry based rationale of this research utilises an exploratory action research approach in order to iteratively plan, act, observe and reflect [28], whilst integrating design thinking as a cultural transformation within a leading Australian airport corporation. The action research approach is demonstrated in Fig. 2. Fig. 2 builds upon action research methodologies in design practice [29], and action research methodologies for change and development [30]. In this case, the methodology begins with the planning of how design led innovation as a theory can be disseminated across the airport corporation. The second phase of this process, involves teaching stakeholders the skills and tools of design led innovation through the practice of theory within the digital strategy project. Phase 3 involves observing, interviewing and documenting the opportunities and barriers that arise from using design led innovation within this project and any impact of the approach across the business. Phase 3 is the formal data collection phase of this methodology. Phase 4 is the reflective stage which involves the formal dissemination of the opportunities and barriers that arise from design led innovation within academic and industry domains.

The embedded nature of the action research approach [31] offers the ability to analyse multiple levels of data within the single setting to document any cultural transformation present during the 12-month research period. An action research approach offers insight into the cultural dynamics present within the business in order to plan and act to teach the design led approach within a dynamic organisational context [30, 32]. New knowledge is created for the internal stakeholders of the airport corporation through the dissemination of the design led innovation tools and skills. New knowledge is created by the researcher that addresses how to best disseminate the tools and skills of design led innovation in response to organisational barriers and gaining momentum through opportunity identification [29].

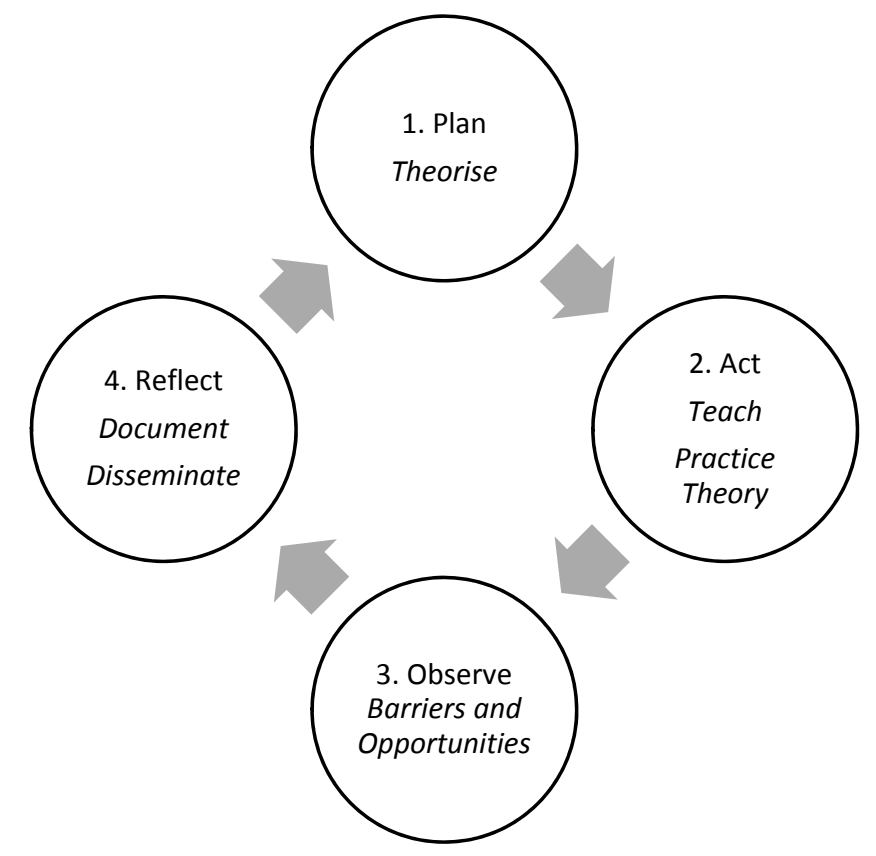

Fig 2. Exploratory Action Research Cycle $[31,32]$

\section{B. Data collection and analysis}

The qualitative action research method [33] uses three research approaches [34] over a period of 12 months to teach, test, document, and overcome organisational barriers to design led innovation. This paper documents findings from the first 6 months of the program. The underlying epistemological position for the undertaking of this research project is interpretative [35]. Twenty semi-structured interviews [36] [35] with internal stakeholders were completed lasting approximately 60 minutes each. With participant consent, these interviews were recorded then transcribed for the purpose of analysis. Stakeholders were selected from all departments of the corporation, and vertically within these departments from the position of senior management to support staff. The foci of the semi structured interviews explored current innovation processes, the perception and role of design within the corporation, and the challenges that faced stakeholders in their day to day employment.

One focus group [37] [35] was run with five internal stakeholders in the format of a design led internal workshop to develop ideas for the development of the mobile application as a component of the greater digital strategy. A reflective journal [32] has been kept in line with the reflective nature of action research which documents day to day events present within the research context of the Australian airport. All data collected will be analysed using a thematic approach to uncover research themes through coding and the identification of patterns [38] [33]. The thematic analysis seeks to discover regularities in language and attitude, the discerning of themes, 
and the interpretation and identification of existing processes [39].

\section{RESULTS}

The results from the research protocol, are split into barriers to design led innovation and opportunities arising from design led innovation as the two main categories. Within barriers are three subthemes which surround current blockers to design led innovation within the organisational context of a leading Australian airport. These subthemes are core business mindset, smart following and reputation and regulation. Within opportunities are three subthemes relating to emergent opportunities built upon the platform of design led innovation. These subthemes are customer engagement, idea generation, and business to business leverage.

\section{A. Barriers to design led innovation}

Barriers to design led innovation were centered on the importance of core business and the existence of regulations. The notion of smart following was raised as an attitude toward innovation based on presumed resource limitations and a risk adverse culture.

\section{1) Core buiness mindset}

The core business of the airport was associated with the fundamental operation of landing and departing aircraft. Stakeholders were focused heavily on the operation of the airport:

"Innovation comes from everybody - that's how you develop innovation. It's hard to get that message out there with people that are only concerned with the operations and the safety and security of the airport. I think regulation is more of a mindset barrier to innovation." P8

This mindset of operation and infrastructure was frequently encountered within the data collection phase. A mindset associated with the sole operation and maintenance of infrastructure with conservative attitudes toward innovation is highlighted below:

"Any sort of infrastructure company isn't going to be high on innovation. You just need to provide a good service to the infrastructure." P7

Part of core business mindset was the industry reliance on quantitative customer data as a means for analysis of business performance and marketing potential. A qualitative design led approach to the development of the digital strategy encountered barriers in project planning based on the scope of the deep customer insights. These barriers came from both internal stakeholders and business partners. The notion that the qualitative design approach was not "statistically viable" because of the limited participant numbers was encountered at various points of project planning. This is well documented within the reflected journal. A reluctance to use the narrative approach was also observed. Interacting with customers was also referred to as collecting market data, as opposed to customer engagement or gathering deep customer insights. Overcoming these barriers came from clear presentation of the importance of context within qualitative design research methods along with the support from the airport design champion.

\section{2) Smart following}

Smart following was raised as a strategy for implementation of innovation within the airport corporation. Whilst stakeholders saw the positives from adopting innovation from industry leaders, there was general agreement that the airport was not a current leader due to its relative size and global positioning.

"I think we are a smart follower. I think what we do well is to see what others are doing and copy and do it in our own way." P2

The notion of risk taking and a fear of failure accompanied this notion of smart following. Risk was associated with trying new things and any level of uncertainty with an outcome. Being different was described as a shift away from the smart following strategy.

"Being different-we're very safe, cautious company - we don't like taking risks, don't like failure. It makes it difficult if you want to try new things." P10

Whilst a risk averse and cautious business in the highly regulated airport sector and broader aviation industry is necessary to uphold the safe and secure operation of an airport, this mindset may also extend to prevent innovation outside of the required operational boundaries such as customer experience.

\section{3) Reputation and regulation}

An interesting balance between reputation and regulation appeared across many levels of the organisation with varying effects upon the significance of an innovation culture. The airport was noted to be under pressure to innovate in order to remain significant within the aviation industry.

"If we don't innovate to prepare the airport to be compliant for those aircraft and airspace design that can handle that, then we will either fall off the perch from our legislative requirements, but more importantly we will fall off the perch as being considered a full and complete airport". P12

Conversely, innovations that diverted from the core business of the airport performance such as technology innovations were scrutinised within media domains due to flight delays which effected on time performance of the airport.

"Thinking outside the box, or innovatively, has been scrutinised in the media recently because on-time performance is seen as our primary job”. P16 
A clear level of pressure on innovation from industry and the public places a unique pressure on airports to closely manage innovations surrounding operations, and to justify innovations in areas outside of core business, such as digital media. The core business or primary role of providing on-time performance is noted as the bottom line of an airports performance.

\section{B. Opportunities arising from design led innovation}

Opportunities arising from the use of design led innovation in the development of a digital strategy were formed from design led innovation's high emphasis on customer and stakeholder engagement through the iterative cycle of generating provocations. Generating these provocations acted as platform for encouraging creativity and stakeholder collaboration with a focus on giving the customer a voice. Testing these provocations with passengers in particular opened up new critical channels for meaningful customer dialogue.

\section{1) Customer engagement}

Customer engagement was traditionally seen as a channel activated through marketing, data trends, and ancillary revenue streams. Testing provocations with customers provided rich dialogue from which new deep insights were generated. Connecting with passengers through meaningful dialogue also tested assumptions about passenger experience within the airport.

"We had assumptions about what our passengers thought. But we were able to uncover so many issues, emotions and reasons that we will be able to tap into and address to improve their experience. I think we have a much greater emphasis on all our stakeholders now." P1

The deep customer insights stage provided a real sense of momentum to internal stakeholders that a positive improvement in passenger experience could be made with high impact through the digital strategy.

"Consistently building a service portfolio that revolves around deeper insights and anticipates customer needs will lead to much deeper relationship with passengers and opportunities in the future. There are opportunities everywhere to create a truly awesome place if we can just get some momentum to think outside the traditional airport model." P19

Momentum is noted as an important opportunity in this case to driving a new way of thinking when reconsidering the business model of an airport. Whilst some airport stakeholders were quite visionary in their thoughts, their actions towards implanting these visions were countered by existing organisational barriers. Primarily, ideas were just that - ideas. Without a proposition or case example, creative ideas quickly lost momentum within the organisational landscape. Design led innovation provided the platform in this case to collaborate across departments to encourage these visionary thinkers to contribute to idea generation that was closely linked to the gathering of deep customer insights.

\section{2) Idea generation}

Locating visionary thinkers and testing their creative ideas as provocations through design led innovation proved to be a successful strategy in moving to a business case stage gate within internal policy. Internal airport stakeholders were given a voice and encouraged to contribute innovative ideas within the design led innovation workshops. These workshops were run with stakeholders representing the corporation's departments from positions of senior management through to coordinators and support staff. Reflective journal notes document these design led workshops as being dynamic environments where stakeholders contributed and built upon ideas from the viewpoint of the customers' needs and desires. Stakeholders used narratives and design tools effectively to explore and design customer experiences with a digital service. Whilst divergent thinking was noted as a strength, the transition to convergent thinking was a point of weakness.

This reflective journal documentation is supported by stakeholder feedback reporting that the design led workshop was an "excellent and enjoyable approach that facilitated great new ideas within the group". Since the workshop, the hosting department has also conceptualised their current innovation programs collectively into a funnel diagram representing stages of their innovation process from environmental scanning and implementation status. This came from need to "document and make more transparent" the innovation process used within the strategic development of the airport. This has been seen as a positive move toward a more self-aware innovation culture.

\section{3) Business to business leverage}

The strategic use of deep customer insights as a new tool for customer engagement and a platform for future innovation has been leveraged by the commercial face of the corporation. The process of gathering deep customer insights was adopted and reapplied by the commercial face in strengthening business to business relationships through the co-exploration and codesign of passenger experience. Deep customer insights were gathered through the co-design of narratives tested with passengers. The project was led by the airport retail coordinator in collaboration with a prominent retail partner. The project was facilitated by the design led catalyst (first author). The retail coordinator provided the following feedback:

"In this case, we had our assumptions about what the customers thought of the [company x's] products. This project has given us a deeper understanding of our passengers, their journeys, and the process of travelling and currency exchange use. [Company x] worked with us to develop these insights and have now been provided extensive data directly from passengers." $P 1$ 
The success of this project has been reflected by national interest from other major Australian airport retail departments. The use of a design led approach to deep customer insights is now considered a tool which the airport retail department can utilise in exploring new passenger insights as a tenancy service to business partners and retailers.

\section{DISCUSSION}

The organizational challenges and barriers in using a design led innovation approach to the development of a digital strategy are founded within existing layers of business model. Ingrained within the airport business model is an emphasis on sustaining performance through the successful operation of an airport's core business - the arrival and departure of planes to service passengers and the greater community [3]. The mindset associated with the operational duties of an airport is undisputable; an airport must deliver excellence, safety and security in operational standards in order to service to the public and private sectors. This culture toward operational excellence and precision is becoming of an airport with aspirations of achieving "world's best" status. However, this mindset should also be matched with the desire to be innovative and the structure to encourage and implement innovations. The skills to articulate this desire to be innovative through action are encouraged through the integration of a design thinking culture [6] which has been disruptive to the existing organisational culture.

Developing a design thinking culture toward value creation through design led innovation has provided the necessary platform for deeper customer engagement and internal design capability building. Gathering deep customer insights has encouraged a level of empathy for external stakeholders [13] fortified by a digital strategy's potential to solve new identified problems that customers and stakeholders face. The iterative testing of possible solutions with customers has provided the necessary dialogue loop that may allow for an ability to anticipate future needs as new business opportunities [6]. Aligning the vision of the airport corporation to customer needs through the design led approach has encouraged stakeholders to generate ideas internally within the organisation using design thinking skills such as narratives and persona design to articulate their ideas [12]. This is a crucial step from smartly following industry leaders in adopting and reapplying innovations [22] and provides greater governance by internalising the creative component of an innovation project. Stakeholders can now develop and test ideas through propositions that utilise the exploratory and iterative nature of design [6]. Greater ownership, the potential for new intellectual property and disruptive innovations [19] are typically encouraged within innovation generating [22], or design led organisations [6].

The journey of implementing a design thinking culture within the organisation is in its mid phases of development. While stakeholders could utilise design thinking tools in exploring customer needs, conceptual skills still focused on divergent thinking within the context of idea reframing activities [9]. Transitioning to convergent thinking where a single idea or concept is to be explored and improved, is planned as the next action research phase by the design led catalyst $[12,26]$. Using narratives [12] within idea generation workshops encouraged ideas to be immediately contextualised within the setting of the airport with empathy evident toward the needs and desires of the customers [13]. The particular airport department housing the design led catalyst has implemented a conceptual innovation funnel to provide greater transparency and project accountancy within their innovation pipeline. The innovation funnel relies on a proof of concept stage which presents either working prototypes or in the culture of innovation adoption [22]: case studies of success from industry leaders. Deep customer insights provide an avenue to test new to world, or radical services or products through co-design with customers and stakeholders [6]. The fail fast component of design led innovation provides the ability to test ideas in a new way within the current innovation funnel, allowing for the quick transition and contextualisation of ideas into business opportunities. Whether deep customer insights alone as a prototype of concepts constitute a proof of concept, or more traditional high resolution prototypes with tangible feedback is needed, is a topic which is yet to be explored within the business case phase of this particular innovation process. Low resolution prototypes such as the design provocations used within the deep customer insights phase can be harnessed to reduce risk within a project as customers and stakeholders contribute to the evaluation and refining of possible solutions from feedback. Presenting low resolution prototypes to stakeholders who are not aware of the design led approach may be the source of organisational barriers within business case phase of this project. Identifying these barriers will be a focus of future research outputs that track the journey of the development of a digital strategy through design led innovation. What is clear from the ongoing provocations through design led innovation, is that the generation of new ideas is at the forefront of the strategic department and is driven by a focus on the customer and stakeholders, rather than embedding immediate technology solutions without customer engagement.

In shifting from a smart follower to a leader in the aviation industry, it is essential that interest and desire to see innovative projects move to implementation is built within internal stakeholders as a cultural transformation which challenges the business as usual mentality. As the design led catalyst and design champion of design led innovation are based in the strategic development group of the airport corporation, the development of design capabilities within internal stakeholders is well positioned to interact with projects during early development phases where stakeholder needs can be explored and new meanings interpreted.

The design led approach encourages and sets a framework in place for the collaboration between internal stakeholders [15]. It was noted through the results, that an opportunity came from the collaborative nature of the idea generation. 
Through iterative narrative development with internal stakeholders, a voice was given to middle management that allowed them to contribute to the development of the digital strategy which was previously being developed at a more senior management level. In many cases, it was middle management and support staff that held a mature and creative ability matched with high levels of empathy for the customer that allowed them to work through problems within a narrative [12] and identify new meanings [14].

As many stakeholders had travelled by air using many airports, assumptions held about the experience of the customer were continuously evaluated. The process of collecting deep customer insights in particular provided a substantial platform to test these assumptions about passenger experience and passenger needs. Not only were these assumptions critiqued by other stakeholders, they were tested with customers on a weekly basis. The gathering of these deep customer insights also tested and validated qualitative market data, adding another layer to the shift toward beyond adopting innovations [22].

\section{IMPLICATIONS AND FUTURE WORK}

Design led innovation provides the relevant framework for the integration of design as a capability within a business to allow internal stakeholders to propose new ideas about business operation. By grounding these ideas through the iterative testing and gathering of deep customer insights, a business can move beyond adopting innovations as a smart follower, to producing innovations that specifically target the unique needs of their own customers and stakeholders. In this case, design led innovation has been implemented within the specific project development of a digital strategy which aims to improve passenger experience and leverage potential revenue opportunities through the digital delivery of personally tailored information. The development of the digital strategy using a design led approach has increased internal stakeholder collaboration and encouraged creativity. Increased collaboration design direction offers a new level of transparency for the generation of ideas as documented within this paper. The framework of design led innovation has provided a platform to move beyond adopting innovations from recognised industry leaders to an organisational transformation towards provoking and testing possible digital strategy solutions with actual customers and stakeholders within this particular leading Australian airport.

Such a shift within the mindset of stakeholders can create the drivers for a broader revaluation of an existing business model, and this momentum is seen as a necessary milestone in the broader design led innovation journey. The iterative nature of provoking and testing possible digital solutions develops internal problems solving capabilities and the ability to reframe problems based on new identified meanings. A business or corporation looking to shift their strategy from one of smart following, or innovation adoption, to leading within an industry can apply design led innovation as the necessary groundwork to transform and innovate at a business model level.

\section{A. Future Work}

Future work will continue the dissemination of design led innovation and the skills of design thinking within the leading Australian airport corporation part of a continued shift toward a design led business model. In particular, the shift from a proposition to the design of strategy is seen as the next phase of the design led innovation research program. This phase will look to identify how a proposition can inform strategy. Continued dissemination of design led innovation will also seek to reinforce the learning's of stakeholders. Achieving autonomy over the design skills whereby stakeholders feel confident and able to identify and select approaches of design thinking $[9,12,13]$ is also a challenge within the wider dissemination of design led innovation. The dissemination of skills of design thinking is limited to a select number of stakeholders at this stage, given the progress of the 12 month embedded action research phase of design led innovation program. Stakeholders must possess the motivation and be able to articulate the value of design thinking to their colleagues in order for a design thinking culture to be truly adopted. Building and sustaining momentum during the dissemination of design led innovation is critical in successfully overcoming organisational barriers that may stall a design led shift towards innovation - such as the barriers that have been identified in this paper. It is clear that momentum is building within this project, supported by the strength of the opportunities arising from design led innovation. Championing these successes more broadly across the organisation, particularly with operational orientated staff, is planned as the next phase of the action research program to encourage and cement interest and debate of innovation, and reveal the broader value of design led innovation.

\section{REFERENCES}

[1] Frank, L., Business models for airports in a competitive environment. One sky, different stories. Research in Transportation Business \& Management, 2011. 1(1): p. 25-35.

[2] de Neufville, R., Airports of the Future: The Development of Airport Systems, in International Symposium and Exposition in Celebration of 100 years of powered flight 2003: Dayton, Ohio.

[3] Kasarda, J., Aerotropolis: Airport driven-urban development, in The Future of Cities, U.L. Institute, Editor. 2000: Washington DC.

[4] Charles, M., et al., Airport futures: Towards a critique of the aerotopolis model. Futures, 2007. 39(2007): p. 1009-1028.

[5] Kasarda, J., Logistics and the rise of the Aerotropolis. Real Estate Issues, 2001(Winter): p. 43-48.

[6] Bucolo, S., C. Wrigley, and J. Matthews, Gaps in organizational leadership : linking strategic and operational activities through design-led propositions. Design Management Journal, 2012. 7(1): p. 18-28.

[7] Kimbell, L., Rethinking Design Thinking: Part 1. Design and Culture, 2011. 3(3): p. 285-306.

[8] Dell'Era, C. and R. Verganti, Collaborative Strategies in Design-intensive Industries: Knowledge Diversity and Innovation. Long Range Planning, 2010. 43(1): p. 123-141. 
[9] Dorst, K., The core of 'design thinking' and its application. Design Studies, 2011. 32(6): p. 521-532.

[10] Cross, N., Designerly Ways of Knowing. 2006, Dordrecht.: Springer-Verlag.

[11] Buchanan, R., Rhetoric, Humanism, and Design, in Discovering Design: Explorations in Design Studies, R. Buchanan and V. Margolin, Editors. 1995, The University of Chicago Press: Chicago and London. p. 22-66.

[12] Beckman, S. and M. Barry, Developing Design Thinking Capabilities. Academic Research Library, 2008. 24(82).

[13] Brown, T., Change By Design. 2008, New York: HaperCollinns.

[14] Verganti, R., Design-Driven Innovation: Changing the Rules of Competition by Radically Innovating what Things Mean. 2009, Boston: Havard Business Press.

[15] Bucolo, S. and J. Matthews, A Conceptual Model to Link Deep Customer Insights to both Growth Opportunities and Organisational Strategy in SME's as part of a Design Led Transformation Journey, in Design Management Toward A New Era of Innovation. 2011: Hong Kong Convention and Exhibition Center, Hong Kong.

[16] Martin, R.L., The Design of Business: Why design thinking is the next competitive advantage. 2009: Harvard Businees Press.[17]Ian,

[18] Taneja, N.K., The Passenger Has Gone Digital and Mobile: Accessing and Connecting Through Information and Technology. 2011, Farnham: Ashgate Publishing Ltd.

[19] Christensen, C., The Innovators Dilemma: New Technologies that cause great firms to fail. 1997, Boston: Harvard Business Press.

[20] Bucolo, S. and J. Matthews, Design Led Innovation : exploring the synthesis of needs, technologies and business models, in Participatory Interaction Conference. 2001

[21] Goedeking, P., Networks in Aviation : Strategies and Structures. 2010, Springer: Dordrecht.

[22] Damanpour, F. and D. Wischnevsky, Research on innovation in organizations: Distinguishing innovation-generating from innovation-adopting organization. Journal of Engineering and Technology Management, 2006. 23.
[23] Carlopio, J., Creating Strategy by Design. Design principles and practices: An international journal, 2009. 3(5): p. 155-166.

[24] Porter, M.E., Competitive strategy: techniques for analyzing industries and competitors. 2004, New York: Free.

[25] Jeanne, L., Learning to use design thinking tools for successful innovation. Strategy \& Leadership, 2011. 39(5): p. 13-19.

[26] Wrigley, C., Educating the 'Design Led Catalyst' for change, in 5th International Association of Societies of Design Research Conference: Consilience and Innovation in Design. 2013: Tokyo, Japan.

[27] Eisenhardt, K.M., Building Theories from Case Study Research. The academy of Management Review, 1989. 14(4): p. 532-550.

[28] Zuber-Skerritt, O., Action Research in Higher Education. 1992, London: Kogan page.

[29] Swann, C., Action Research and the Practice of Design. Design Issues, 2002. 18(1): p. 49-61.

[30] Somekh, B. and C. Ebooks, Action research: a methodology for change and development. 2006, Maidenhead: Open University Press.

[31] Yin, R., Case Study Research. 1984, Los Angeles: Sage Publications.

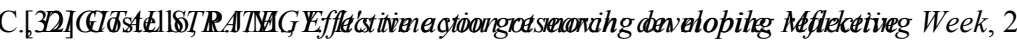
thinking and practice. 2011, New York: Continuum.

[33] Miles, M. and A.M. Huberman, Qualitative Data Analysis: An Expanded Sourcebook. 1994, Thousand Oaks: Sage Publications.

[34] Tracy, S.J., Qualitative research methods: collecting evidence, crafting analysis, communicating impact. 2013, Chichester, U.K: Wiley-Blackwell.

[35] Myers, M.D., Qualitative Research in Business \& Management. 2009, London: Sage.

[36] Given, L., Semi-Structured Interview. 2008, Sage Publications.

[37] Krueger, R.A. and M.A. Casey, Focus groups: a practical guide for applied research. 2009, Los Angeles: SAGE.

[38] Braun, V. and V. Clarke, Using thematic analysis in psychology. Qualitative Research in Psychology, 2006. 3(2).

[39] Tesch, R., Qualitative Research: Analysis types and software tools. 1990, New York: Falmer. 